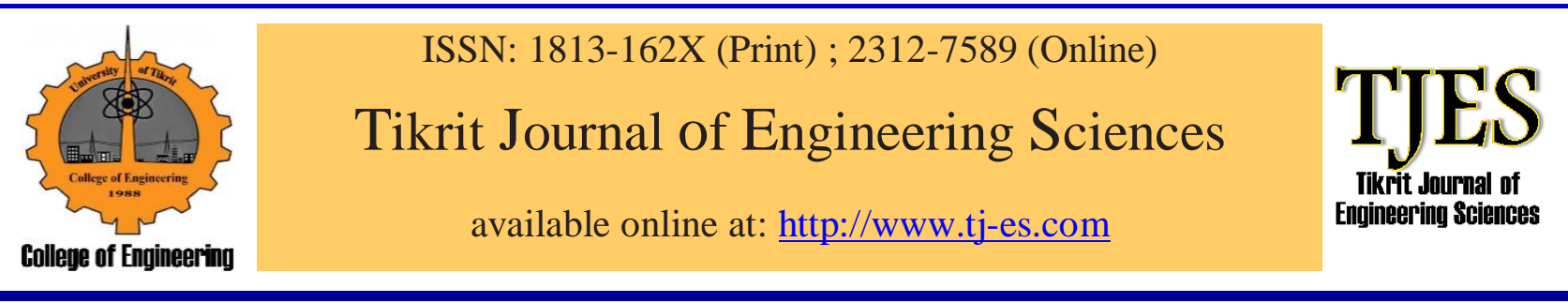

Hamdoon OM, Al-Ali BM. Modeling and Simulation of a Desiccant Evaporative Cooling System. Tikrit Journal of Engineering Sciences 2019; 26 (3): 10-18.

\section{Omar M. Hamdoon * Burhan M. Al-Ali}

Mechanical Engineering Dept., Mosul University, Mosul, Iraq

\title{
Modeling and Simulation of a Desiccant Evaporative Cooling System
}

\begin{abstract}
A B S T R A C T
This paper studies the performance of a proposed desiccant assisted air conditioning system operating under the hot and dry climate conditions of Mosul city, Iraq. The proposed system consists of three stages: indirect/direct evaporative cooler, an enthalpy wheel, and a traditional vapor compression system. The performance of the suggested system is compared with that of the vapor compression system operating at the same conditions. The simulation results showed that an optimum rotational speed of $12.5 \mathrm{rpm}$ is required for the enthalpy wheel to achieve the best system performance. The simulation results also showed the ability of the proposed system to achieve a power consumption saving of $51.03 \%$, in the ventilation mode, and $22.93 \%$, in the mixing mode with a ventilation mixing ratio of 0.4 when compared to the vapor compression system.
\end{abstract}

(c) 2019 TJES, College of Engineering, Tikrit University

\section{DOI: http://doi.org/10.25130/tjes.26.3.02}

نمذجة ومحاكاة منظومة تبريد تبخيري مُجَفَف

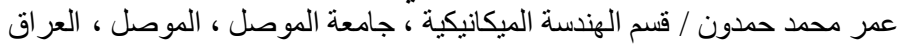

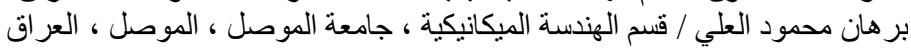

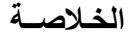

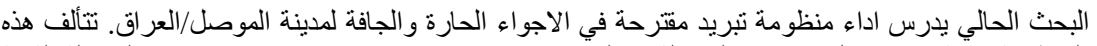

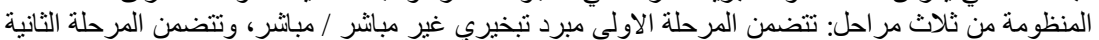

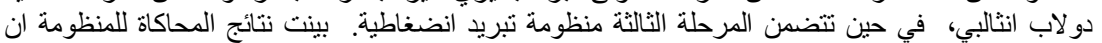

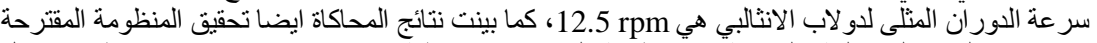

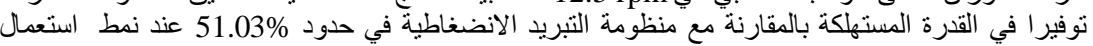
هو اء خارجي كليا، ونتوفيرا في القدرة المستهلكة في حدود 22.93\% عند استعمال مزيج من الهواء الهن وبنسبة مزج

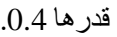

الكلمات الدالة: التبريد التبخيري المباشر / غير المباثر، التبريد بالتجفيف، دو لاب الانثالبي ،المحاكاة.

\section{Abbreviations}

$A_{\mathrm{c}^{v}}^{\mathrm{n}} A_{s}^{\mathrm{n}}$ : Single channel cross-sectional and interface area, $\mathrm{m} 2$.

Afic, Afid: Area per unit volume of cooling tower and direct evaporative cooler packing, $\mathrm{m} 2 / \mathrm{m} 3$.

$\mathrm{C}$ : Heat capacity rate, $\mathrm{kJ} / \mathrm{s} . \mathrm{K}$.

Cpda, Cplw: Specific heat of dry air and liquid water, $\mathrm{kJ} / \mathrm{kg} . \mathrm{K}$.

Cps, Cpwv: Specific heat of support material and water vapor, $\mathrm{kJ} / \mathrm{kg}$.K.

F: Desiccant material fraction.

Gwc,Gwd: Mass velocity of water through cooling tower and direct evaporative cooler packing, $\mathrm{kg} / \mathrm{m} 2 . \mathrm{s}$.

$\mathrm{Ha}, \mathrm{Hv}$ : Enthalpy of air and water vapor, $\mathrm{kJ} / \mathrm{kg}$. hca,hcw: Air and water convection heat transfer coefficients, W/m2 .K.

hmw: Mass transfer coefficients through enthalpy wheel, $\mathrm{kg} / \mathrm{m} 2 . \mathrm{s}$.

Lef: Lewis factor.

$\left\{\mathrm{L}_{\mathrm{xc}} \mathrm{L}_{\mathrm{yc}} \mathrm{L}_{\mathrm{zc}}\right\}$ : Lengths in the $\mathrm{x}, \mathrm{y}$, and $\mathrm{z}$ directions for cooling tower, $\mathrm{m}$.

$\left\{\mathrm{L}_{\mathrm{xd}} \mathrm{L}_{\mathrm{yd}} \mathrm{L}_{\mathrm{zd}}\right\}$ : Lengths in the $\mathrm{x}, \mathrm{y}$, and $\mathrm{z}$ directions for direct evaporative cooler, $\mathrm{m}$.

$\left\{\mathrm{L}_{\mathrm{xh}}, \mathrm{L}_{\mathrm{yh}}, \mathrm{L}_{\mathrm{zh}}\right\}$ : Lengths in the $\mathrm{x}, \mathrm{y}$, and $\mathrm{z}$ directions for heat exchanger, $\mathrm{m}$.

Lw: Enthalpy wheel depth, $\mathrm{m}$.

mac, mad: Mass flow rate of air and water flowing to the cooling tower, $\mathrm{kg} / \mathrm{m} 2 . \mathrm{s}$.

mwc,mwd: Mass flow rate of air and water flowing to the direct evaporative cooler, $\mathrm{kg} / \mathrm{m} 2 . \mathrm{s}$. 
$\mathrm{N}, \overline{\mathrm{N}}$ : Enthalpy wheel rotational speed in rpm and rps.

NTU: Number of transfer unit.

Patm: Atmospheric pressure, $\mathrm{Pa}$.

ps: Saturation pressure, $\mathrm{Pa}$.

qad: Heat of adsorption, $\mathrm{kJ} / \mathrm{kg}$.

Re: Reynolds number.

Ta,Twb: Dry and wet bulb air temperature, ${ }^{\circ} \mathrm{C}$.

Tw: Enthalpy wheel wall temperature, ${ }^{\circ} \mathrm{C}$.

T $\omega$ : Water temperature, ${ }^{\circ} \mathrm{C}$.

Ua: Air stream velocity in enthalpy wheel channel, $\mathrm{m} / \mathrm{s}$.

$\mathrm{V}_{\mathrm{d}}^{\mathrm{n}}{ }^{\mathrm{B}} \mathrm{V}_{\mathrm{w}}^{\mathrm{n}}$ : Volume of desiccant layer and wall in single channel, m3.

W: Water content of the desiccant (adsorption capacity), $\mathrm{kg}$ water/kg dry air.

wmax: Maximum water content, kg water/kg dry air.

$\overline{\mathrm{x}}$ : Non-dimensional length (enthalpy wheel), $\overline{\mathrm{X}}=\mathrm{x} / \mathrm{L}_{\mathrm{w}}$.

$\overline{\mathrm{X}}_{s} \overline{\mathrm{Y}}$ : Non-dimensional lengths (cooling tower packing), $\overline{\mathrm{X}}=\mathrm{x} / \mathrm{L}_{\mathrm{xe}}, \overline{\mathrm{Y}}=\mathrm{y} / \mathrm{L}_{\mathrm{yc}}$.

$\mathrm{X}_{s} \mathrm{Y}$ : Non-dimensional lengths (heat exchanger),

$\mathrm{X}=\mathrm{x} / \mathrm{L}_{\mathrm{xh}}, \mathrm{Y}=\mathrm{y} / \mathrm{L}_{\mathrm{yh}}$.

$\widehat{\mathrm{X}}, \widehat{\mathrm{Y}}:$ Non-dimensional lengths (direct evaporative cooler) $\widehat{\mathrm{X}}=\mathrm{x} / \mathrm{L}_{\mathrm{xd}}, \widehat{\mathrm{Y}}=\mathrm{y} / \mathrm{L}_{\mathrm{yd}}$.

Ya: Air humidity ratio, $\mathrm{kg} / \mathrm{kg}$.

Yw: Humidity ratio of the air in equilibrium with moist desiccant, $\mathrm{kg} / \mathrm{kg}$.

Ysw: Humidity ratio of the air at local water temperature, $\mathrm{kg} / \mathrm{kg}$.

\section{Greek Symbols}

$\tau$ : Non-dimensional time, $\tau=\mathrm{t} \overline{\mathrm{N}}$

\section{Subscript}

a, d, w, s: Air, desiccant, water, Support material.

O, R, S: Outdoor, room, and supply air conditions.

\section{Introduction}

In the last decade, evaporative cooler and hybrid desiccant cooling technologies have increased as an alternative or as an addition to conventional vapor compression systems [1]. The following items include a demonstration of the previously mentioned systems:

Hybrid Desiccant Cooling System: There are many types of the hybrid desiccant cooling system; one of them consists of the following items [2]:

1- Enthalpy wheel: The enthalpy wheel consists of concentric thin metal rings desiccant material-clad. Each ring is formed of a plain metal layer above which there is another layer folded to form the required shape of the air channel. These channels have a rectangular, triangular or sinusoidal shape depending on the manufacturing process. The rings are fixed with each other by means of spokes. The desiccant materials used in the enthalpy wheel are characterized by the high ability to adsorb humidity from the air or releasing humidity to the air when it passes through the wheel as a result of the difference in the water vapor pressure between the air and the desiccant material. The most well-known desiccant material used for this purpose is the regular density silica gel [3]. The wheel is divided into two parts, the ambient humid air passes through the first part and the dry air returning from the conditioned space passes through the second part. This wheel transmits the sensible heat and humidity between these two streams. Humidity moves between the layer of desiccant material and the air stream and from the higher humidity ratio to the lower one because of the difference in the water vapor pressure.

2- Vapor compression system: In order to reduce the temperature and the humidity ratio of the air leaving the enthalpy wheel to the supplying conditions.

-Indirect/direct evaporative cooler (I/DEC): The most well-known cooling systems used in the desert weather are the evaporative coolers. The principle of these systems is to use the water evaporation for cooling the air streams directly or indirectly. In the (I/DEC) the air, firstly, passes through the indirect evaporative cooler exchanger and then it passes over the wet surfaces of the direct evaporative cooler. Water circulating through the indirect evaporative cooler is cooled by a cooling tower and then piped to an air/water heat exchanger. The primary air stream is pre-cooled without humidification in the heat exchanger. Further cooling of the air takes place in the direct evaporative cooler [4].

\section{The proposed system}

The proposed system combines an (indirect/direct evaporative cooler system) with (hybrid desiccant cooling system). As shown in Fig. 1, the proposed system mainly consists of: indirect/direct evaporative cooler (air/water cross flow heat exchanger, cross flow wet-cooling tower, and direct evaporative cooler), enthalpy wheel (silica gelbased enthalpy wheel), vapor compression system, induced and exhaust fan, pumps, as well as mixing damper to mix the air leaving the enthalpy wheel with the returning air in order that the mixture passes through the cooling coil. When this damper is closed, the system operates in the ventilation mode, and when this damper is opened the system operates in the mixing mode. In this case, the function of the damper is to control the ventilation mixing ratio (VMR). This is defined by the following equation: $\mathrm{VMR}=\mathrm{m}_{\mathrm{a} 3} / \mathrm{m}_{\mathrm{a} 4}$. It can be noted that: $\mathrm{VMR}=1$ for ventilation mode, and, $\mathrm{VMR}<1$ for mixing mode .The processes of this system can be explained as follows:

O-1: Air loses the sensible heat in the air/water heat exchanger as a result of exchanging the sensible heat with the circulated water.

1-2: Adiabatic cooling of the air takes place in the direct evaporative cooler.

2-3: Dehumidification of air through the enthalpy wheel.

3-4: Mixing of the air coming from the enthalpy wheel with the returning air occurs.

4-S: The temperature and the humidity ratio of the air coming out the enthalpy wheel are still not suitable for the supply conditions, for this reason there is a need to reduce the temperature of the air and its humidity ratio by passing it through the cooling coil.

S-R: The air supplied to the space.

R-5: The dry air coming from the space acquires the humidity as it passes through the enthalpy wheel.

5-6: The air coming from the enthalpy wheel is used to cool the circulating water through the indirect evaporative cooler. 


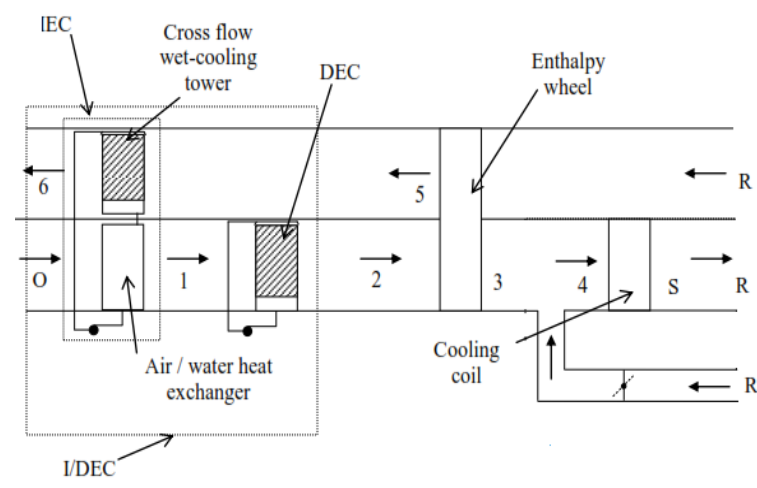

Figure. 1. Schematic of the proposed system

\section{System modeling Enthalpy wheel}

Fig. 2.a illustrates a typical enthalpy wheel of length $L_{w}$ and diameter $d_{w}$. The wheel rotates at a speed of $\mathrm{N}$ (rpm) being cyclically exposed to two physically separated air streams, which are in counter flow arrangement. These streams, labeled (supply air) and (return air), are fed to the wheel through two ducts, separated by a wedge to prevent mixing, thereby dividing the wheel into two equal flow sections (return section, and supply section). The wheel is composed of numerous channels parallel to the rotation axis with relatively small cross-sectional areas. Consequently a flow channel is said to be operating either in (supply period) or (return period) according to its current location. Regardless of the operating period, the air in the channels is simply referred to as (process air) throughout this section. The transport phenomena occurring in these systems are usually analyzed by considering a single channel structure, bounded by an adiabatic and impermeable surface in the direction perpendicular to the process stream. The walls of each channel are composed of a desiccant layer thickness $\delta_{\mathrm{d}}$ laid upon an impermeable supporting structure of thickness $\delta_{\mathrm{s}}$, as shown in Fig. 2.b.

Because of symmetry, a shape surrounded by dashed line is used as the physical model. Appling mass and energy conservation laws to an infinitesimal control volume within a channel of the enthalpy wheel the following set of governing equations in non-dimensional form can be obtained [5]:

$$
\begin{aligned}
& \mathrm{dY}_{\mathrm{w}}=\mathrm{a}_{1} \mathrm{dT}_{\mathrm{w}}+\mathrm{a}_{2} \mathrm{dw} \\
& \frac{\partial \mathrm{Y}_{\mathrm{I}}}{\partial \mathrm{x}}=\mathrm{a}_{\mathrm{a}}\left(\mathrm{Y}_{\mathrm{w}}-\mathrm{Y}_{\mathrm{a}}\right) \\
& \frac{\partial \mathrm{w}}{\partial \tau}=\mathrm{a}_{4}\left(\mathrm{Y}_{\mathrm{a}}-\mathrm{Y}_{\mathrm{w}}\right) \\
& \frac{\partial \mathrm{T}_{\mathrm{W}}}{\partial \tau}=\mathrm{a}_{5}\left(\mathrm{~T}_{\mathrm{a}}-\mathrm{T}_{\mathrm{w}}\right)+\mathrm{a}_{6}\left(\mathrm{Y}_{\mathrm{W}}-\mathrm{Y}_{\mathrm{a}}\right) \\
& \frac{\partial \mathrm{T}_{\mathrm{II}}}{\partial x}=\mathrm{a}_{\mathrm{g}}\left(\mathrm{T}_{\mathrm{w}}-\mathrm{T}_{\mathrm{a}}\right)
\end{aligned}
$$

These sets of governing equations are subject to the following boundary and initial condition:

$$
\begin{aligned}
& \mathrm{T}_{\mathrm{a}}(0, \tau)=\mathrm{T}_{\mathrm{a}_{2}}, \mathrm{Y}_{\mathrm{a}}(0, \tau)=\mathrm{Y}_{\mathrm{a}_{2}} \\
& \mathrm{~T}_{\mathrm{a}}(1, \tau)=\mathrm{T}_{\mathrm{a}_{\mathrm{R}}}, \mathrm{Y}_{\mathrm{a}}(1, \tau)=\mathrm{Y}_{\mathrm{a}_{\mathrm{R}}} \ldots \ldots . . \\
& \mathrm{T}_{\mathrm{w}}(\overline{\mathrm{x}}, 0)=\mathrm{T}_{\mathrm{w}_{\mathrm{in}}},{ }, \mathrm{W}(\overline{\mathrm{x}}, 0)=\mathrm{w}_{\max }
\end{aligned}
$$

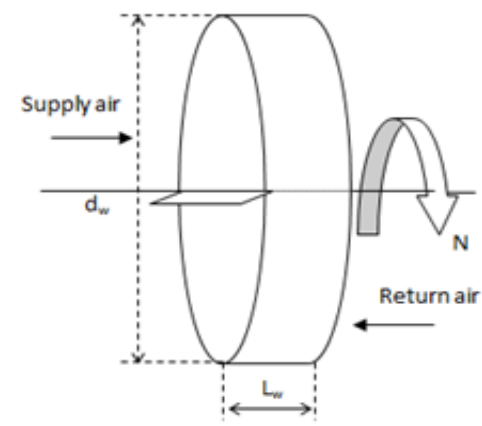

(a)

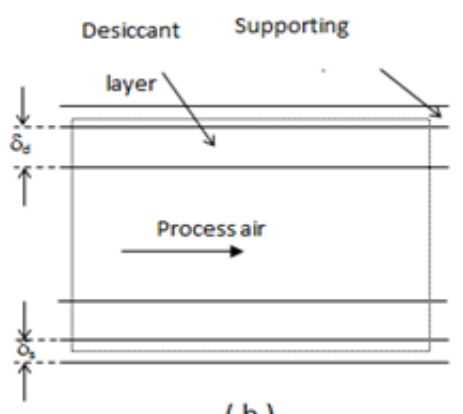

(b)

Figure. 2. Enthalpy wheel; (a): Statement diagram, (b): Single flow channel structure.

Where;

$\mathrm{a}_{1}=\left[\frac{0.622 \mathrm{RH}\left(\frac{\mathrm{P}_{\mathrm{atm}}}{\mathrm{P}_{\mathrm{g}}}\right)\left(\frac{\mathrm{dP}_{\mathrm{g}}}{\mathrm{dT}_{\mathrm{W}}}\right)}{\left(\frac{\mathrm{Patm}_{\mathrm{atm}}}{\mathrm{P}_{\mathrm{g}}^{2}}-\mathrm{RH}\right)^{2}}\right]$

$\mathrm{a}_{2}=\left[\frac{0.622\left(\frac{\mathrm{Patm}_{\mathrm{ag}}}{\mathrm{P}_{\mathrm{g}}}\right)\left(\frac{\mathrm{dRH}}{\mathrm{dw}}\right)}{\left(\frac{\mathrm{P}_{\mathrm{atm}}}{\mathrm{P}_{\mathrm{g}}}-\mathrm{RH}\right)^{2}}\right]$

$\mathrm{a}_{\mathrm{a}}=\left(\frac{\mathrm{A}_{\mathrm{s}}^{\mathrm{n}}}{\mathrm{A}_{\mathrm{c}}^{\mathrm{n}}}\right)\left(\frac{\mathrm{h}_{\mathrm{mw}}}{\mathrm{u}_{\mathrm{a}}}\right)$

$\mathrm{a}_{4}=\left(\frac{\mathrm{A}_{\mathrm{a}}^{\mathrm{n}}}{\mathrm{V}_{\mathrm{d}}^{\mathrm{n}}}\right)\left(\frac{\mathrm{h}_{\mathrm{mw}} \mathrm{P}_{\mathrm{a}}}{\rho_{\mathrm{d}} \overline{\mathrm{N}}}\right)$

$\mathrm{a}_{5}=\frac{\left(\frac{A_{g}^{u}}{V_{m}^{m}}\right) h_{m w} P_{a} q_{a d}}{P_{W} \bar{N}\left[(1-f) C p_{s}+f\left(C p d_{d}+w C p l_{w}\right)\right]}$ 


$$
\mathrm{a}_{6}=\frac{\left(\frac{A_{\mathrm{u}}^{\mathrm{u}}}{V_{\mathrm{m}}^{\mathrm{u}}}\right) \mathrm{h}_{\mathrm{cw}}}{\mathrm{P}_{\mathrm{W}} \overline{\mathrm{N}}\left[(1-\mathrm{f}) \mathrm{Cp_{ \textrm {s } }}+\mathrm{f}\left(\mathrm{Cpd}+\mathrm{wCpl}_{\mathrm{W}}\right)\right]}
$$

$$
\mathrm{a}_{7}=\left(\frac{A_{\mathrm{s}}^{\mathrm{n}}}{\mathrm{A}_{\mathrm{c}}^{\mathrm{n}}}\right)\left(\frac{\mathrm{h}_{\mathrm{cw}}}{\rho_{\mathrm{a}} \mathrm{Cpd}_{\mathrm{a}} \mathrm{u}_{\mathrm{a}}\left[1+\frac{\mathrm{Cpw}_{\mathrm{V}}}{\mathrm{Cpd}_{\mathrm{a}}} \mathrm{Y}_{\mathrm{a}}\right]}\right)
$$

$\mathrm{P}_{\mathrm{s}}$ is the saturation pressure at wall temperature, and is given by [6]:

$$
P_{g}=e^{\left(22.1964-\frac{3816.44}{T_{W}+226.87}\right)}
$$

And, $\mathrm{RH}$ is the relative humidity. The relation between the relative humidity on the surface of desiccant material and the equilibrium adsorption capacity at constant temperature is usually called "equilibrium adsorption isotherm". The equilibrium adsorption isotherm for regular density silica gel is given by [6]:

$$
\mathrm{RH}=\begin{array}{cccccc}
0.0078- & 0.05759 & \mathrm{w} & + & 24.16554 & \mathrm{w}^{2} \\
-124.78 \mathrm{w}^{3}+204.226 \mathrm{w}^{4} & \ldots & (7) & &
\end{array}
$$

Using a finite difference method, Eqs. 1, 3, and 4 can be approximated at node $(i+1, n+1 / 2)$, where $n$ represents time step and i represents position step. Eqs. 2 and 5 can be approximated at nodes $(i+1 / 2, n+1)$. The properties of process air and channel wall can be approximated at nodes $(i+1 / 2, n+1)$, and $(i+1, n+1 / 2)$. After substituting we have system of algebraic equations and the Gausselimination method [7] is used to solve this system of equations.

\section{Indirect/Direct Evaporative Cooler}

As shown in Fig. 1, the main components of the indirect/direct evaporative cooler used in the present study are:

1- Cross flow wet-cooling tower.

2- Air/water cross flow heat exchanger.

3- Direct evaporative cooler.

The modeling of the above mentioned components are given in the following sections.

\section{Cross Flow Wet-Cooling Tower}

The heat and mass transfer characteristics of the cooling tower can be determined by the conservation equations of energy and mass in the packing. By considering a control volume in the packing of cooling tower, the governing equations representing the mass and energy balance in the non-dimensional form can be written as follows [8]:

$$
\frac{\partial G_{W E}}{\partial T}=-E_{1}\left(Y_{D W}-Y_{a}\right)
$$

$$
\frac{\partial \mathrm{Y}_{\mathrm{aI}}}{\partial \mathrm{X}}=\mathrm{E}_{2}\left(\mathrm{Y}_{\mathrm{aW}}-\mathrm{Y}_{\mathrm{a}}\right)
$$

$$
\frac{\partial H_{a}}{\partial \mathrm{X}}=\mathrm{E}_{2}\left[\begin{array}{c}
\mathrm{H}_{\mathrm{a}_{\mathrm{sW}}}-\mathrm{H}_{\mathrm{a}}+(\mathrm{Lef}-1) \\
\left\{\mathrm{H}_{\mathrm{a}_{\mathrm{aW}}}-\mathrm{H}_{\mathrm{a}}-\mathrm{H}_{\mathrm{v}}\left(\mathrm{Y}_{\mathrm{aw}}-\mathrm{Y}_{\mathrm{a}}\right)\right\}
\end{array}\right]
$$

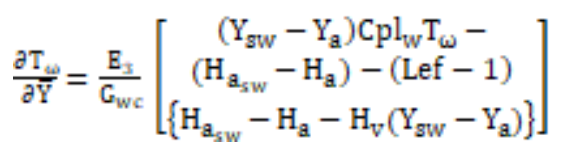

These sets of governing equations are subject to the following boundary condition:

$$
\begin{aligned}
& \mathrm{H}_{\mathrm{a}}(0, \overline{\mathrm{Y}})=\mathrm{H}_{\mathrm{a}_{5}}, \mathrm{Y}_{\mathrm{a}}(0, \overline{\mathrm{Y}})=\mathrm{Y}_{\mathrm{a}_{5}} \text { ， } \\
& \mathrm{G}_{\mathrm{wc}}(\overline{\mathrm{X}}, 0)=\mathrm{G}_{\mathrm{W} 1}, \mathrm{~T}_{\omega}(\overline{\mathrm{X}}, 0)=\mathrm{T}_{\omega 1} \\
& \text { Where: } \mathrm{E}_{1}=\mathrm{A}_{\mathrm{fic}} \mathrm{L}_{\mathrm{yc}} \mathrm{h}_{\mathrm{me}} \mathrm{E}_{2}=\frac{A_{\mathrm{fic}} \mathrm{L}_{\mathrm{xc}} \mathrm{h}_{\mathrm{mIc}}}{\mathrm{G}_{\mathrm{irc}}} \text {, } \\
& \mathrm{E}_{\mathrm{a}}=\frac{\mathrm{A}_{\mathrm{Iix}} \mathrm{L}_{\mathrm{yc}} \mathrm{n}_{\mathrm{mL}}}{\mathrm{CpI}_{\mathrm{w}}}
\end{aligned}
$$

Lef is the Lewis factor and given by [9]:

$$
\text { Lef }=0.865^{a v a g}\left(\frac{Y_{\text {av }}+0.622}{Y_{\text {a }}+0.622}-1\right) /\left[\ln \left(\frac{Y_{\text {aw }}+0.622}{Y_{a}+0.622}\right)\right]
$$

$\mathrm{h}_{\mathrm{mc}}$ is the mass transfer coefficient. The mass transfer coefficient through the PVC cellular film packing is given by [10]:

$$
\mathrm{NTU}_{\mathrm{c}}=2.3\left(\frac{\mathrm{m}_{\mathrm{Mc}}}{\mathrm{m}_{\mathrm{wL}}}\right)^{-0.28}
$$

Where $\mathrm{NTU}_{\mathrm{c}}$ is the number of transfer unit of a cooling tower.

All the above governing equations are of first-order. Therefore, first derivatives can be approximated by firstorder backward finite-difference expressions. The resulting system of algebraic equations, are solved iteratively using Successive Over Relation method [11].

\section{Heat Exchanger Modeling:}

The heat exchanger used in the present study is a cross flow plate fin, flat tubes type heat exchanger. A schematic of this heat exchanger is given in Fig. 3.a. In this study, the inlet air velocity uniform, and the temperature variations between the tubes were also assumed to be negligible, therefore, only a single fin and tube assembly is considered as shown in Fig. 3.b. Two coupled governing energy balance equations are needed to analyze the heat transfer through the exchanger, one for the air flow and the other for the water flow. By considering a control volume element, in water and air sides, the non- 
dimensional governing equations representing the energy balance can be written as follows [12]:

$$
\frac{\partial \mathrm{T}_{\mathrm{a}}}{\partial \mathrm{X}}=-\mathrm{NTU}_{\mathrm{a}}\left(\mathrm{T}_{\mathrm{a}}-\mathrm{T}_{\mathfrak{W}}\right)
$$

And the water side:

$$
\frac{\partial \mathrm{T}_{\omega}}{\partial \mathrm{Y}}=-\mathrm{NTU}_{\omega}\left(\mathrm{T}_{\mathrm{a}}-\mathrm{T}_{\omega}\right)
$$

Where:

$$
\mathrm{NTU}_{\mathrm{a}}=\frac{2 \mathrm{U} \mathrm{L}_{\mathrm{xh}}\left\llcorner_{\mathrm{yh}}\right.}{\mathrm{C}_{\mathrm{a}}} \quad \mathrm{NTU}_{w}=\frac{2 \mathrm{U} \mathrm{L}_{\mathrm{xh}}\left\llcorner_{\mathrm{yh}}\right.}{\mathrm{C}_{\mathrm{w}}}
$$

The above equations are first-order. These first derivatives can be approximated by first-order backward finite-difference expressions, then are solved using the Successive Over Relation method across a twodimensional domain [11].
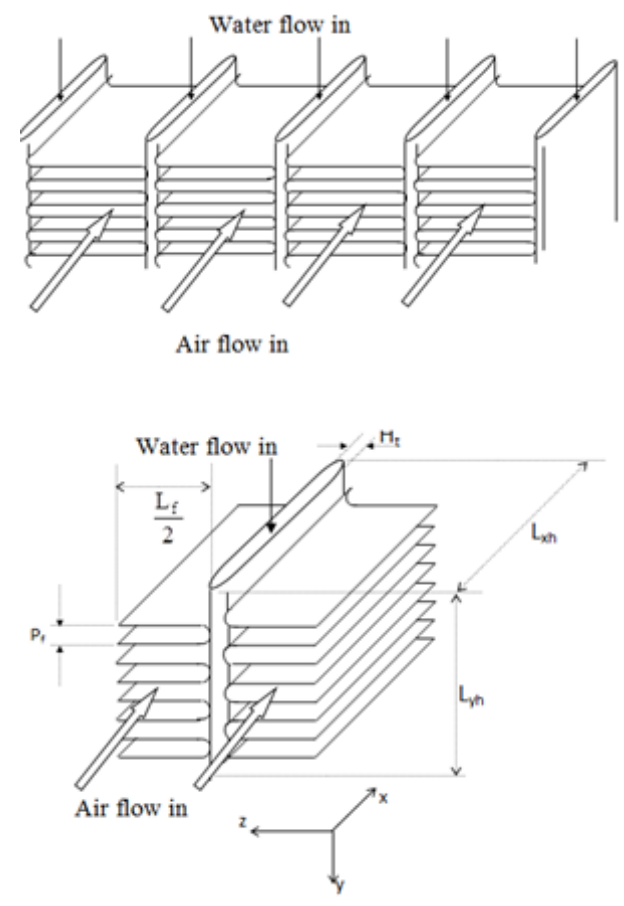

Figure. 3. (a): Air/water cross flow plate heat exchanger, (b): Schematic of one pair flow channels.

\section{Direct Evaporative Cooler Modeling:}

In the direct evaporative cooler, the heat and mass transferred between air and water decrease the air dry bulb temperature, and increase its humidity, keeping the enthalpy constant. The recirculated water is running in a closed loop and reaches an equilibrium temperature equal to entering air wet bulb temperature. By considering a control volume in the packing of evaporative cooler, the dimensionless governing equations representing the mass and energy balance can be written as follows:

- The mass balance for the control volume:

$$
\begin{aligned}
& \frac{\partial \mathrm{G}_{\mathrm{wd}}}{\partial \widehat{\mathrm{Y}}}=-\mathrm{D}_{1}\left(\mathrm{Y}_{\mathrm{gw}}-\mathrm{Y}_{\mathrm{a}}\right) \\
& \frac{\partial \mathrm{Y}_{\mathrm{a}}}{\partial \widehat{\mathrm{X}}}=\mathrm{D}_{2}\left(\mathrm{Y}_{\mathrm{gw}}-\mathrm{Y}_{\mathrm{a}}\right) \ldots
\end{aligned}
$$

- The energy balance for the control volume:

$$
\begin{aligned}
& \mathrm{T}_{\mathrm{a}}=\mathrm{T}_{\mathrm{w}}+\mathrm{D}_{\mathrm{a}} \frac{\left(\mathrm{Y}_{\mathrm{gw}}-\mathrm{Y}_{\mathrm{a}}\right)}{\text { Lef }} \\
& \mathrm{T}_{w}=\mathrm{T}_{\mathrm{wb} 2} \mathrm{~mm} \mathrm{~mm} \mathrm{~m} \mathrm{~m}
\end{aligned}
$$

$$
\begin{aligned}
& \text { Where } \mathrm{D}_{1}=\mathrm{A}_{\mathrm{fid}} \mathrm{L}_{\mathrm{yd}} \mathrm{h}_{\mathrm{md}} \quad, \quad \mathrm{D}_{2}=\frac{A_{\text {rid }} \mathrm{L}_{\mathrm{xud}} \mathrm{h}_{\mathrm{mid}}}{\mathrm{G}_{\mathrm{add}}} \text {, } \\
& \mathrm{D}_{3}=\frac{\mathrm{h}_{\mathrm{V}}}{\mathrm{CP}_{\mathrm{a}}}
\end{aligned}
$$

Dowdy and Karabash [13] presented a correlation to determinate the convective heat transfer coefficients in a rigid cellulose evaporative media, their correlation is given by:

$$
\mathrm{Nu}=0.1\left(\frac{\mathrm{L}_{\mathrm{c}}}{\mathrm{L}_{\mathrm{xul}}}\right)^{\mathrm{u.1.12}} \operatorname{Re}^{0.8} \mathrm{Pr}^{1 / 3}
$$

The above equations are first-order. Their first derivatives can be approximated by first-order backward finitedifference expressions. The resulting equations are solved by Successive Over Relation method across a twodimensional domain.

\section{The Proposed System Performance Index}

System performance index can be listed as follows:

- Cooling coil load:

$$
\text { Q_ev=m_(a_4 ) (h_(a_4 )-h_(a_5 )) }
$$

Total power consumption $[4,14]$ :

$$
\mathrm{WT}=\mathrm{Wc}+\mathrm{WF}+\mathrm{Wp}+\mathrm{Ww}
$$

Where WT: total power consumption, WC: power consumption of the compressor, WF: power consumption of the fans, Ww: power consumption of the wheel motor, Wp: power consumption of the pumps.

- Coefficient of performance of the system:

The Coefficient of performance of the system is computed by:

$$
\mathrm{COP}=\mathrm{Qc} / \mathrm{WT}
$$

Where Qc is the cooling production of the system,

Q_c =m_(a_o ) (h_(a_o ) -h_(a_3 ) )+m_(a_4 ) (h_(a_4 )h_(a_s ) )

- Power saving: The system power saving describes the ability of the proposed system to achieve a saving in the 
consumed power in comparison with the vapor compression. This is defined as follows:

PS $=\left[\left(W_{-}\left(T_{-}\right.\right.\right.$vcs $)-W_{-}\left(T_{-}\right.$ss $\left.)\right) / W_{-}\left(T_{-}\right.$vcs $\left.)\right] \times 100$ (22)

Where WTss and WTvcs are the total power consumption of the proposed and vapor compression systems respectively.

\section{The Complete Model of the System}

The models of each component which is used in the present study are gathered together to form the complete model of the system. The general solution is on the basis of ignoring any gain or loss of heat for air and water, when the air passes though the fans and ducts, and when the water passes though the pumps and pipes. The simulation of the proposed system is carried out by using the successive substitutional method. This method of solution depends on hypothesizing one or more variables at the beginning of the solution which continues by using the equations till getting new values for the hypothesized variable or variables. These variables are repeated successively till the beginning of the calculation. This calculation cycle is repeated till getting the required convergence. In the current study, $\left(\varepsilon_{\text {erro }} r \leq 1.0 \times 10-3\right)$ is the error criterion, on the basis of which, the required convergence is verified. Therefore, there is a need to simulate the complete model of the proposed system. The solution program has been written to be run with the aid of FORTRAN 90 (Microsoft Developer studio Copy right(1994-1995). For the solution domains, the numbers of points that have been taken are given as: Enthalpy wheel $(n=20)$, Cooling tower $(\mathrm{Ni}=20, \mathrm{Nj}=60)$, Heat exchanger $(\mathrm{Mi}=20, \mathrm{Mj}=60)$, Direct evaporative cooler $(\mathrm{Ki}=30, \mathrm{Kj}=60)$.

\section{Proposed System Simulation Results}

The performance of the proposed system is compared with that of vapor compression system. Both systems are simulated in accordance with the conditions given as:

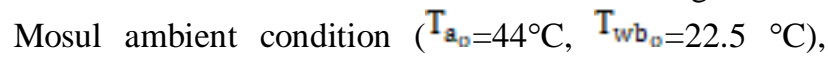
Room Total Heat (7.0 KW), Indoor/return air condition $\left(\mathrm{T}_{\mathrm{a}_{\mathrm{R}}=24^{\circ} \mathrm{C},} \mathrm{T}_{\left.\mathrm{wb}_{\mathrm{k}}=16^{\circ} \mathrm{C}\right) \text {, Room sensible Heat Factor }}\right.$ (0.75). From the above data, and by assuming the apparatus dew point temperature is $7{ }^{\circ} \mathrm{C}$, it can be conducted that for the vapor compression system at ventilation mode, the supply air conditions of the air

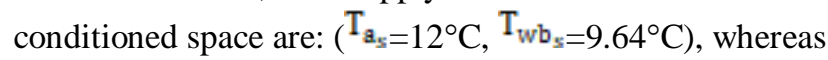
the air mass flow rate through the cooling coil is 0.431 $\mathrm{kg} / \mathrm{s}$. The two previous values of air mass flow rate and supply air conditions are applied as well in simulating of the proposed system at ventilation or mixing mode. The input simulation data of the proposed system is illustrated in Table 1.

\section{Effect of Rotation Speed of the Enthalpy Wheel}

The effect of the enthalpy wheel rotation speed on the

Table 1: Input simulation data

\begin{tabular}{|c|c|c|}
\hline \multicolumn{2}{|r|}{ Name (Symbol), unit } & $\begin{array}{c}\text { Value } \\
\text { Default } \\
\text { (Max.- } \\
\text { Min.) }\end{array}$ \\
\hline \multirow{5}{*}{ 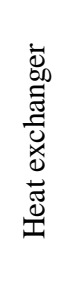 } & Height $\left(L_{y h}\right), m$ & 0.3 \\
\hline & Width $\left(L_{z h}\right), m$ & 0.6 \\
\hline & Depth $\left(L_{x h}\right), m$ & 0.2 \\
\hline & Fin pitch $\left(P_{F}\right), m$ & $2.5 e-03$ \\
\hline & Fin thick. $\left(\delta_{\mathrm{F}}\right), \mathrm{mm}$ & 0.1 \\
\hline \multirow{5}{*}{ 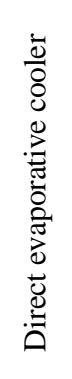 } & Height $\left(L_{y d}\right), m$ & 0.3 \\
\hline & Width $\left(L_{z d}\right), m$ & 0.6 \\
\hline & $\begin{array}{l}\text { Specific surface area } \\
\left(A_{\text {fid }}\right) \mathrm{m}^{2} / \mathrm{m}^{3}\end{array}$ & 370 \\
\hline & Packing thick. $\left(L_{x d}\right), m$ & 0.1 \\
\hline & $\begin{array}{l}\text { Supply water mass } \\
\text { velocity }\left(G_{w 3}\right), . \mathrm{kg} / \mathrm{m}^{2} \mathrm{~s}\end{array}$ & 1.25 \\
\hline \multirow{3}{*}{ 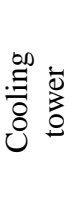 } & Height $\left(L_{y c}\right), m$ & 0.3 \\
\hline & Width $\left(L_{z c}\right), m$ & 0.6 \\
\hline & $\begin{array}{l}\text { Supply water mass } \\
\text { velocity }\left(G_{w 1}\right), \mathrm{kg} / \mathrm{m}^{2} \mathrm{~s}\end{array}$ & 1.0 \\
\hline \multirow{6}{*}{ 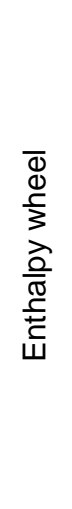 } & Outer dia. $\left(D_{0}\right), m$ & 0.6 \\
\hline & Inner dia. $\left(D_{i}\right), m$ & 0.05 \\
\hline & $\begin{array}{l}\text { Thick. of support } \\
\text { structure }\left(\delta_{\mathrm{s}}\right), \mathrm{mm}\end{array}$ & 0.1 \\
\hline & $\begin{array}{l}\text { Rotation speed }(\mathrm{N}) \text {, } \\
\text { rpm }\end{array}$ & $\begin{array}{c}20(5- \\
40)\end{array}$ \\
\hline & $\begin{array}{l}\text { Enthalpy wheel depth } \\
\left(L_{w}\right), m\end{array}$ & 0.3 \\
\hline & $\begin{array}{l}\text { Desiccant layer } \\
\text { thickness }\left(\delta_{\mathrm{d}}\right), \mathrm{mm}\end{array}$ & 0.3 \\
\hline
\end{tabular}

coefficient of performance and power saving are shown in Fig. 4 and Fig. 5. The figures show the evident increase in the coefficient of performance and power saving, along with an increase in enthalpy wheel rotation speed from 5 rpm to $12.5 \mathrm{rpm}$.

Then the increase of wheel rotation speed leads to a decrease in the values of coefficient of performance and power saving. Therefore, the optimum value of rotation speeds is $12.5 \mathrm{rpm}$. The increase of system effectiveness, along with that of the enthalpy wheel rotation speed, is due to the decrease in humidity ratio coming out from the wheel, which leads to a decrease in cooling coil load, and consequently in the power consumption of the compressor.

\section{Effect of the Ventilation Mixing Ratio}

The effect of the ventilation mixing ratio on the system coefficient of performance and power saving of the 
proposed system can be clearly seen in Fig. 6 and Fig. 7. Fig. 6 shows the decrease in the coefficient of performance along with the decrease in the mixing ratio. This decrease in the coefficient of performance is attributed to the decrease in the cooling production; Qc.

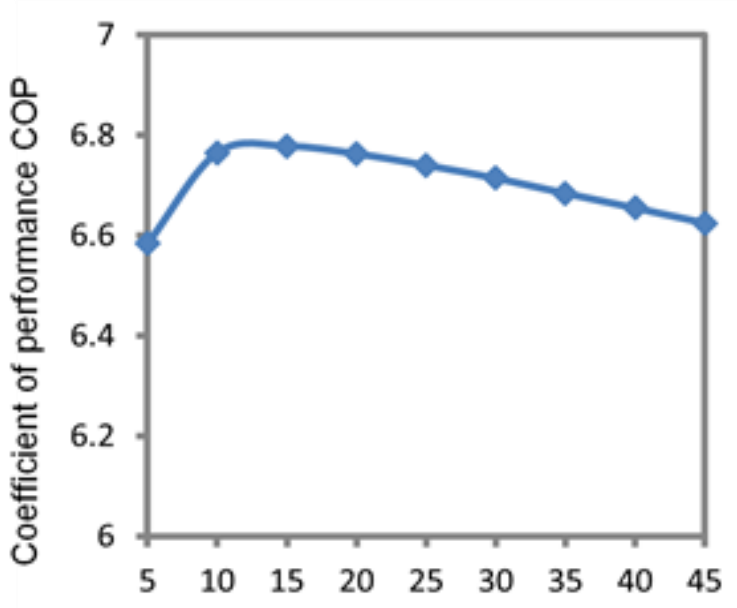

Rotational speed N (rpm)

Figure. 4. Effect of enthalpy wheel rotational

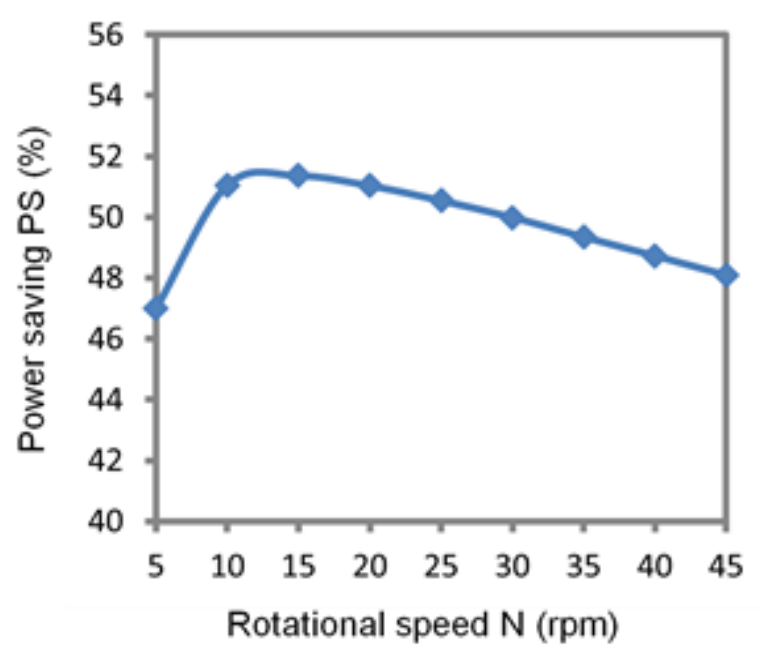

Figure. 5. Effect of enthalpy wheel rotational speed on the power saving

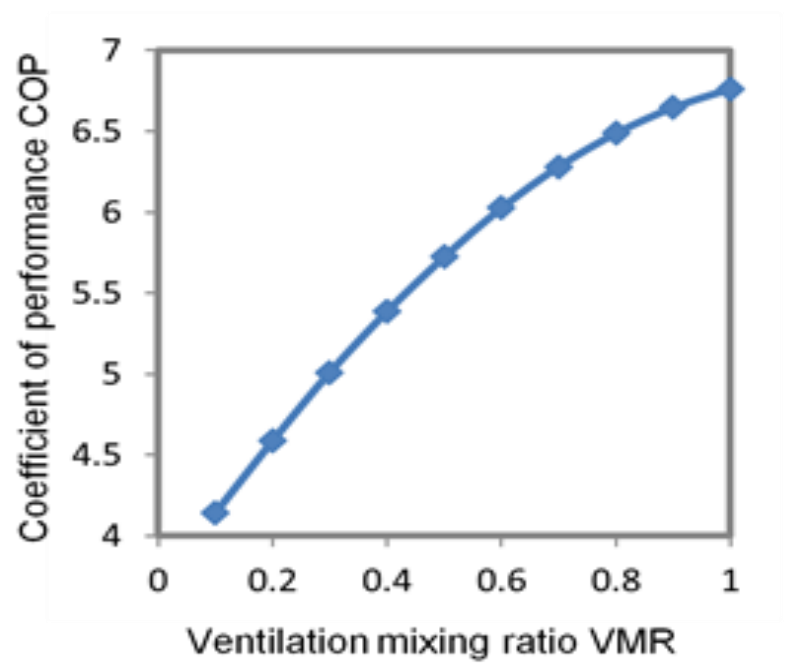

Figure 6 Effect of ventilation mixing ratio on the COP
Fig. 7 shows the reduction in the power saving along with the decrease in the mixing ratio until the power saving value in the proposed system reaches $-3.46 \%$. This means that the power consumed in the vapor compression system is lower than the power consumed in the proposed system. This decrease in the rates of the power saving occurs in spite of the decrease in the total power consumed in the proposed system along with the decrease in the ventilation mixing ratio due to the decrease in the cooling coil load, the compressor power consumption, and the fans power consumption.

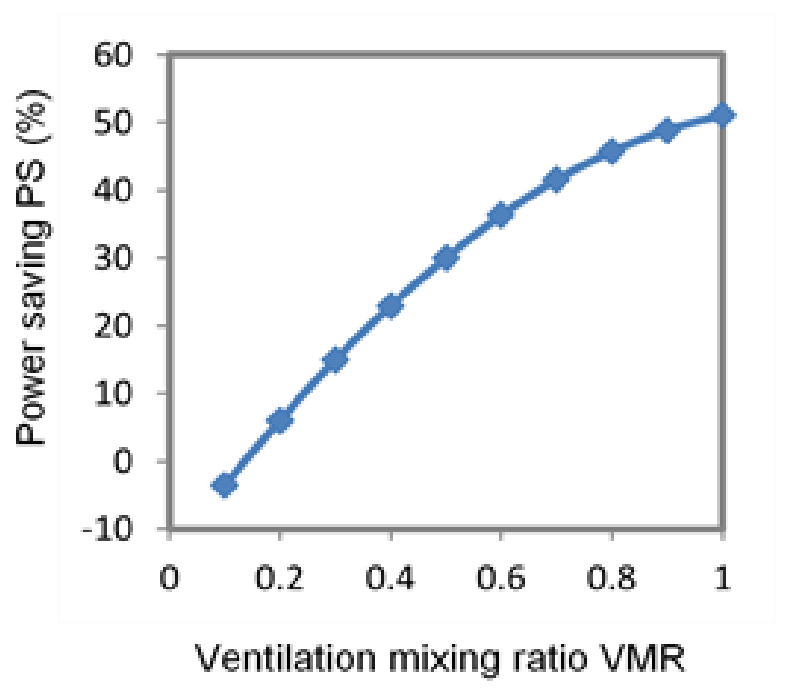

Figure 7 Effect of ventilation mixing ratio on the system power saving

This can be explained by Fig. 8, which shows the cooling processes on the psychometric charts of the proposed system, at two different values of VMR. From the figure, the limited effect of the mixing process can be noted. This is because the air conditions coming out of the enthalpy wheel are close to the air conditions returning from the conditioned space. However, the mixing process does not lead to a clear and tangible change in the supply air conditions of the cooling coil. Conversely, the mixing process of the ambient air with the return air in case of the vapor compression system leads to a big change in the supply air conditions of the cooling coil. Consequently, this leads to a big reduction in the cooling coil load and in the consumed power. For example, in case of proposed system, a mixing process with a ratio of $(\mathrm{VMR}=0.4)$ leads to a change in air conditions from $\left(\mathrm{T}_{\mathrm{a}_{\mathbf{z}}}=24.03{ }^{\circ} \mathrm{C}\right.$,

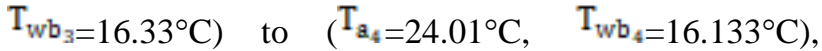
whereas, the same ventilation mixing ratio leads to a change in the ambient air conditions in case of the vapor compression system from $\left(\mathrm{T}_{\mathrm{a}_{\mathrm{a}}}=44^{\circ} \mathrm{C}, \mathrm{T}_{\mathrm{wb}}=22.5^{\circ} \mathrm{C}\right)$ to $\left(\mathrm{T}_{\mathrm{a}_{\mathrm{m}}=32}{ }^{\circ} \mathrm{C}, \mathrm{T}_{\mathrm{wb}_{\mathrm{m}}=13.78}{ }^{\circ} \mathrm{C}\right)$. The decrease in the cooling coil load as a result of the air mixing process is much bigger in case of the vapor compression system. From Fig. 6 and Fig. 7, it can be concluded that the best performance of the proposed system is in a ventilating mode where the power saving of the system in this case 
reaches at $51.03 \%$ in the proposed system. With the change of the system operating mode to a mixing mode, This decrease continues with the increase in the return air ratio (i.e. VMR decrease) until reaching at a ventilation mixing ratio equal to 0.1 , in which the power consumed in the proposed system is higher than the power consumed in the vapor compression system. That is why the proposed system is suitable for the application to operate in a ventilation mode or in a mixing mode with VMR no less than 0.4 . The previous mixing ratio (i.e. $\mathrm{VMR}=0.4$ ) secures a power saving of about (22.93\%).

\section{Effect of Adding the Enthalpy Wheel}

In this section we examine the impact of the enthalpy wheel in the proposed system. The proposed system without the enthalpy wheel consists of two stages: the first one includes indirect/direct evaporative cooler, and the second includes vapor compression system. The performance of the proposed system is compared with that of the two-stage cooling system at the same conditions. The cooling processes in the two systems on the psychometric chart are shown in Fig. 9. From Fig. 9.b, it can be observed that as a result of the high humidity ratio of the supply air to the cooling coil in case of twostage cooling system, it is required to heat the air coming out of the cooling coil in order to approach the supply conditions (point S). This is because of the inability of the cooling coil to transfer the air state from the point 4 to the required supply conditions. Fig. 9 shows the clear effect of the enthalpy wheel to change the supply air conditions of the cooling coil. For example, the supply air conditions of the cooling coil in case of two stage cooling system are

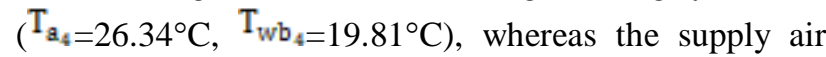
conditions of the cooling coil in case of the proposed

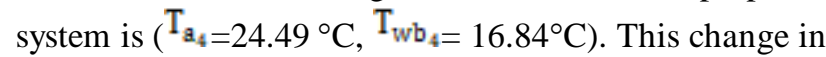
the air conditions is obtained from adding the enthalpy wheels which lead to reducing the cooling coil load and, consequently, increasing the coefficient of performance

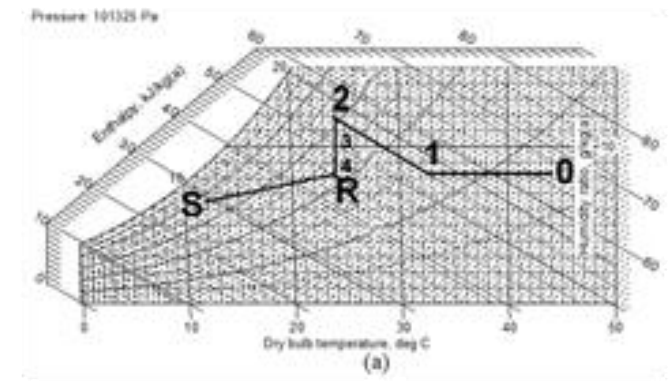

the power saving in the proposed system decreases.

and the power saving, for example the COP are 6.762 and 3.38 for the proposed system and the two stage cooling system respectively. And the PS \% are 51.03 and - 24.325 for the proposed system and the two stage cooling system respectively. This shows the effect of adding the enthalpy wheel in both systems which results in raising the coefficient of performance and increasing the power saving.

\section{Conclusions}

1. The performance of the proposed system has been compared with the performance of a vapor compression system working at the same conditions by comparing the power consumed in the two systems using the power saving factor PS (Eq. 22). This comparison was conducted at a different rotating speed of the wheel $\mathrm{N}$ (Fig. 5) and at a different ventilation mixing ratio VMR (Fig. 7).

2. The simulation results showed that the increase in the rotation speed of the enthalpy wheel $\mathrm{N}$ has a clear effect on increasing the power saving PS of the proposed system. The optimum values of the rotation speeds of the enthalpy wheel is $12.5 \mathrm{rpm}$.

3. The simulation results showed that the best performance of the proposed system is at a ventilation mode $(\mathrm{VMR}=1)$, where the power savings in this mode is PS $=51.03 \%$. With the change of the system operating mode to a mixing mode, the power saving in the proposed system decreases. This decrease continues with the increase in the return air ratio (i.e. VMR decrease) until reaching at a ventilation mixing ratio equal to 0.1 , in which the power consumed in the proposed system is higher than the power consumed in the vapor compression system.

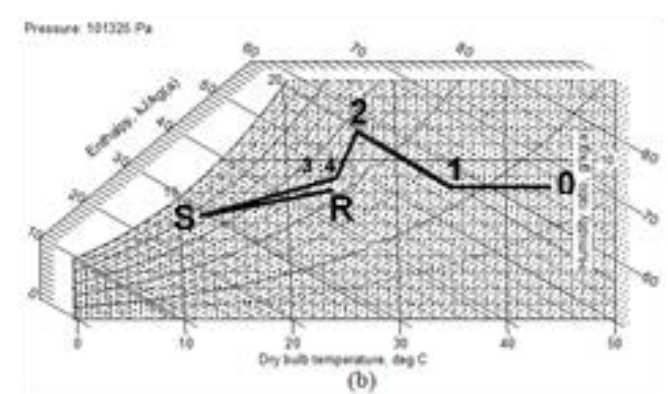

Fig. 8. Proposed system cooling processes for various ventilation mixing ratio. (a: VMR=0.4, b: VMR=1) . 

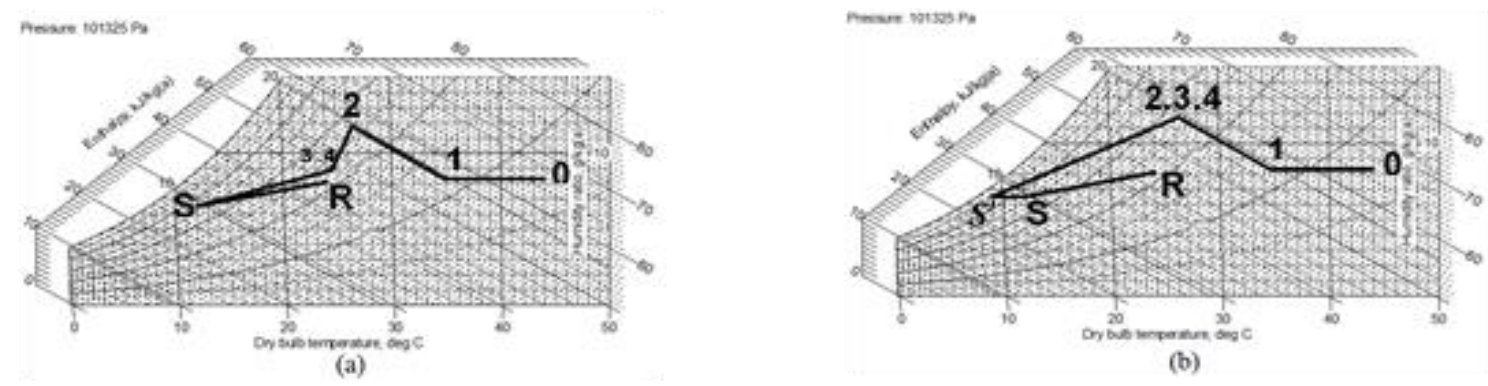

Fig. 9. Cooling processes in the two systems at VMR=1. (a: Proposed system, b:Two stage system).

\section{References}

1. Uçkan I, Yılmaz T, Hürdogan E, Büyükalaca O. "Exergy Analysis of a Novel Configuration of Desiccant Based Evaporative Air Conditioning System", Energy Conversion and Management, 2014; 84: 524-532.

2. Jia X, Dai J, Wu Y, Wang Z. "Analysis on a Hybrid Desiccant Air Conditioning System", Applied Thermal Engineering, 2006; 26 (17-18): 2393-2400.

3. Jeong W, Mumma A. "Practical Thermal Performance Correlations for Molecular Sieve and Silica Gel Loaded Enthalpy Wheels", Applied Thermal Engineering, 2005; 25 (5-6): 719-740.

4. Wang K., Handbook of air Conditioning and Refrigeration, 6th ed., McGraw-Hill; 2000.

5. Mihajlo G, William W. "Influence of Elevated Pressure on Sorption in Desiccant Wheel", Numerical Heat Transfer, part A, 2004; 45 (9): 869-886.

6. Nobrega L, Brum L. "Modeling and Simulation of Heat and Enthalpy Recovery Wheel", Energy, 2009; 34 (12): 2063-2068.

7. Chapra C, Canale P. Numerical method for engineers, 7 th ed., McGraw-Hill; 2015.
8. Kloppers C, Kröger G. "A Critical Investigation into the Heat and Mass Transfer Analysis of Cross Flow Wet-Cooling Towers", Numerical Heat Transfer, part A, 2004; 46 (8): 785-806.

9. Kloppers C, Kröger G. "The Lewis Factor and its Influence on the Performance Prediction of Wet-Cooling Towers", International Journal of Thermal Sciences, 2005; 44 (9): 879-884.

10. Braun E, Klein A., Mitchell W. "Effectiveness Models for Cooling Tower", ASHRAE Transactions, 1989; 95: 164-174.

11. Smith D. Numerical Solution of Partial differential equation, 3th ed., Oxford Applied Mathematics and Computing Science Series; 1985.

12. Fan H. "Modeling a Run-Around Heat and Moisture Recovery System", M.Sc. Thesis, Saskatchewan University, Saskatchewan, Canada 2005.

13. Dowdy A, Karabash S. "Experimental Determination of Heat and Mass Transfer Coefficients in Rigid Impregnated Cellulose Evaporative Media", ASHRAE Transactions, 1987; 93: 382-395.

14. Dai J, Wang Z, Zhang F, Yu D. "Use of Liquid Desiccant Cooling to Improve the Performance of Vapor Compression Air Conditioning", Applied Thermal Engineering, 2001; 21 (12):1185-1202. 